\title{
SURVEY METHODOLOGIES AND 3D MODELLING FOR CONSERVATION OF HISTORICAL MASONRY BRIDGES
}

\author{
I. Trizio ${ }^{1}$, A. Marra ${ }^{1}$ *, F. Savini ${ }^{1}$, G. Fabbrocino ${ }^{1,2}$ \\ ${ }^{1}$ ITC-CNR, Construction Technologies Institute-National Research Council, L’Aquila - (ilaria.trizio; marra; savini; fabbrocino)@itc.cnr.it \\ ${ }^{2}$ Department of Biosciences and Territory, StreGa Lab, University of Molise, Campobasso - giovanni.fabbrocino@unimol.it
}

KEY WORDS: infrastructural heritage, knowledge and documentation, digital survey, HBIM, e-government, e-conservation

\begin{abstract}
:
The safeguarding and conservation of built heritage and historical infrastructures represent complex tasks, especially for administrations and stakeholders operating on peculiar and unique territories with specific cultural, social, and economic problems, such as the historical centres of Inner Areas. However, heritage conservation and management processes can be facilitated by multidisciplinary knowledge methodologies based on solutions offered by digital technologies in the field of documentation. This paper aims at defining novel procedures able to enhance available tools towards a real heritage e-government and e-conservation. The integration of laser scanning and photogrammetric survey-based techniques, as well as on the data of the multidisciplinary analysis available in a virtual environment, the implementation of the parametric model of a historical infrastructure has been investigated for assessing the issues related to the preservation and maintenance of these infrastructures, also in relation to their safety and enhancement. The application to a real case study pointed out the opportunities offered by new technologies in the integration of data coming from different research fields, and the reliability of parametric models in visual inspections and, as a consequence, in the planning of interventions of safeguard and conservation as well as those of valorisation of the historical heritage.
\end{abstract}

\section{INTRODUCTION}

The historical built heritage that characterizes urban contexts and minor historical centres is the result of the mutual interaction between man and nature. As a result, several settlements have developed based on the presence of specific natural resources that have oriented the choice of the settlement area, for example, towards the river valley due to their fertile land suitable for farming. The watercourses were crucial for the agricultural and industrial economic development, as documented by the different historical factories, mills and paper factories, but have always represented a challenge mainly related to their crossing. The builders have faced this problem in different historical periods, designing and constructing fords, temporary structures in alterable material or masonry bridges. These structures were designed and built with empirical criteria different from modern ones because based on the rules of art (Inglese and Paris, 2020), and have stood to time and natural events, such as floods and overflows by means of continuous maintenance. These infrastructures represent constructive activities related to local projects, although interventions carried out in a centralized organization of territories and road system are documented, as in the case of the bridges' construction on the Aterno river, in the Abruzzo region, ordered by the Roman emperor Claudius. Some of these historical crossing structures on the Aterno river can be found in the roads still in use even if they have been modified over time according to changing needs related to the transport evolution and a refunctionalization of the original road routes.

Although these historical infrastructures are part of the current road system suffering the issues related to their management and maintenance, they belong to cultural heritage and must be preserved not only in their tangible features but also in the intangible ones, concerning the preservation of historical memory of places.

Therefore, the knowledge and documentation of historical infrastructures for their safeguarding and conservation are complex challenges that can be achieved using a multidisciplinary effort through which it is possible to analyse these artefacts as a whole and in their peculiarities (ICOMOS, 2003; Lubowiecka et al., 2011). In such a context, the current conditions of artefacts should be understood and analysed both from the structural perspective, recurring to visual inspections and monitoring systems (Solla et al., 2011; Rainieri et al., 2018; Omer et al., 2019), and from the historical and cultural point of view, assessing the causes of their construction and the conservation actions that have ensured their survival until today. Therefore, in such a context, it is clear the need of documenting and managing several heterogeneous data, whose complexity is often improved by using digital models enriched with information and semantic data (De Luca, 2011; Messaudi et al., 2018). The HBIMs of the current condition of artefacts are those that best fit, among the several solutions offered by ICT, for archiving data related to the knowledge process of built heritage. In literature can be found several applications to historical bridges (Banfi et al. 2017; Previtali et al., 2019; Conti et al., 2020; Pepe, Costantino and Restuccia Garofalo, 2020; Maietti et al., 2020), but further efforts are necessary for defining a specific workflow that can facilitate the parameterization of historical structures aimed at responding to different specificities.

The paper aims to define, through the application to a specific case study, a workflow to develop an HBIM based on the combination of different survey techniques for the implementation of parametric elements. Moreover, the parametric model of the current conditions of artefact represents an informative hub and a repository capable of storing, managing and accessing information resulting from the knowledge process. At the same time, this model is an IFCbased interoperable tool facilitating the planning and design for ordinary and extraordinary conservation actions.

The integration of digital tools with multidisciplinary researches results supports the conservation of built heritage and the dissemination and valorisation of cultural value. Indeed, the proposed methodology applied to different historical artefacts proves that the local community, main user and owner of this common heritage, can benefit from the digital application in the 
decision phase for designing interventions for the conservation and protection from risks related to its life cycle. It is worth noting that the maintenance actions are crucial for structural conservation and must consider the cultural features of this type of asset. Therefore, the maintenance interventions, based on cognitive investigation, can be planned, designed and manage efficiently using a parametric model, which will preserve the topological location and the technical and operational information facilitating future actions.

\section{FROM E-GOVERNMENT TO E-CONSERVATION OF THE BUILT HERITAGE}

European policy guidelines are moving member states towards the conscious use of innovative tools, addressing the administrations, even of small towns, towards e-government. Therefore, the research presented here, part of a comprehensive project under development at the ITC-CNR L'Aquila branch, aims at standardising and at validating procedures and digital tools that can support public administrations in the management and preservation of their cultural heritage. In such a context, several digital tools applied to different types of artworks on various scales, ranging from the single artefact to the urban context, are being tested.

Result achieved demonstrated the potential of digital semantic models (Marchetti et al., 2017), virtual information systems (Trizio et al., 2019a) and HBIM of single artefacts or architectural complexes (Trizio et al., 2019b; Trizio et al., 2020), within the multidisciplinary data management aiming at adequate conservation of the built heritage, both in its material and intangible features related to cultural value. The latest research has led to moving the studies on parametric digital model towards an HDT (Historic Digital Twin) of the historical artefacts in order to assess the behaviour of the building by analysing the simulations and the consequent response in the virtual model (Marra et al., in press; Marra, Trizio and Fabbrocino, in press). This combination of experiences has led to the development of a new paradigm, the e-conservation of cultural heritage, based on the meaning given to this term, namely the use of innovative digital technologies in the processes of knowledge and analysis of cultural heritage. This approach can deliver novel web-based digital tools designed according to the Internet of Things (IoT) paradigm to public administrations for the management of assets according to shared processes. Furthermore, e-conservation will allow administrations to share with citizens the decision choices concerning the preservation actions on their heritage according to the indications of the Faro Convention and in line with the principles of e-government provided by the OECD within the report on the Digital Government Index (OECD, 2020).

Finally, the management of cultural heritage, in its broadest sense and in view of its preservation and enhancement, cannot avoid the territorial analysis and spatial management of data. From this perspective, it is worth moving towards integrated BIM and GIS approaches, developing the so-called CIM, to implement econservation and e-government processes. A critical issue of the BIM and GIS integration, addressed through our research topics, concerns the interoperability between the two environments that are very different from the point of view of data protocols, specifically for the IFC standard of the BIM environment and the CityGML standard of GIS ones (Dall'O', Zichi and Torri, 2020).

\section{THE ATERNO VALLEY AND THE HISTORIC BRIDGE OF FONTECCHIO (AQ)}

The Aterno river is one of the principal water basins of the Abruzzo region; it origins near Montereale, a town in the province of L'Aquila, crosses the L'Aquila valley receiving many minor watercourses before flowing into the Pescara river and the Adriatic Sea. The valley of the Aterno river is divided into high, medium and low according to the altimetry; it presents several characteristics with smoother areas and other more severe and inaccessible due to the presence of the rock massif of Gran Sasso and Sirente Velino. Different points of land orography seem adverse for the construction of the settlements, but this did not avoid the development of the historical centres that today characterize the landscape of this area. Over the century, this valley has represented a relevant natural route providing the development of several historical routes that ensured the exchange between different people and shaped the landscape of these places. Indeed, many routes crossed the valley: from prehistoric ones to the roads of the Italic peoples, from the Roman road network, created as a result of a major renovation program of the road network in the areas of Sabine and Vestine people, until the medieval sheep-tracks, from the routes of the modern era until the $19^{\text {th }}$ century, which gave this road system its current structure (Migliario, 1995; Zenodocchio, 2008).

The resilience of the road system led to continuous conservative interventions over the centuries that have ensured the survival of the infrastructural works built to cross the Aterno starting from the Roman period. The structures in use, whose original facies often was altered by the constant restoration and reconstruction, need a careful analysis for assessing the state of preservation and planning the actions aimed at monitoring and maintenance.

Therefore, more comprehensive research is ongoing to define survey methodologies and an operational workflow for recording and managing data acquired during the knowledge and analysis in a digital environment (Savini et al. 2021; Marra et al., in press; Fabbrocino et al., in review). However, different attention should be addressed to the historical masonry bridges still well preserved that have changed their original function, becoming part of the local network, such as crosswalks or interpasture roads, used for the agricultural management of the territory. Therefore, the cognitive analysis requires a higher effort to reconstruct the original role of the artefacts in relation to the evolution of routes and settlements. These structures must be analysed and monitored like other infrastructures, also considering their cultural value that must be preserved, together with their tangible features, for future generations. These issues require greater attention in the acquisition and management of data derived from structural analysis, visual inspections, archaeological investigations and the analysis of the surfaces degradation and the general state of conservation of the structures. Therefore, one of the research goals is to define specific operational procedures for the survey, documentation and use of data through the use of digital tools ranging from semantic models based on photogrammetry and $360^{\circ}$ virtual systems, to define HBIM for historic bridges.

A masonry arch bridge in the municipality of Fontecchio, a small village near the city of L'Aquila, was selected as a case study to verify the effectiveness of the proposed research methodology. The analysed artefact, called Ponte delle Pietre, is one of the bridges that Emperor Claudius built between 47 and 49 A.D. to facilitate the crossing of the Aterno river. The significance in the original road system caused the successive transformations over time until the medieval renovation carried out on the remains of the Roman bridge, although there is a lack of material evidence about that. The bridge is currently used for the farm road system that facilitates access to agricultural areas, and it is part of a pedestrian route belonging to the network of the Regional Natural Park Sirente-Velino (AQ) paths that leads to the "Pagliare", ancient temporary villages used by farmers in summer to cultivate the land and graze their flocks (Figure 1). 


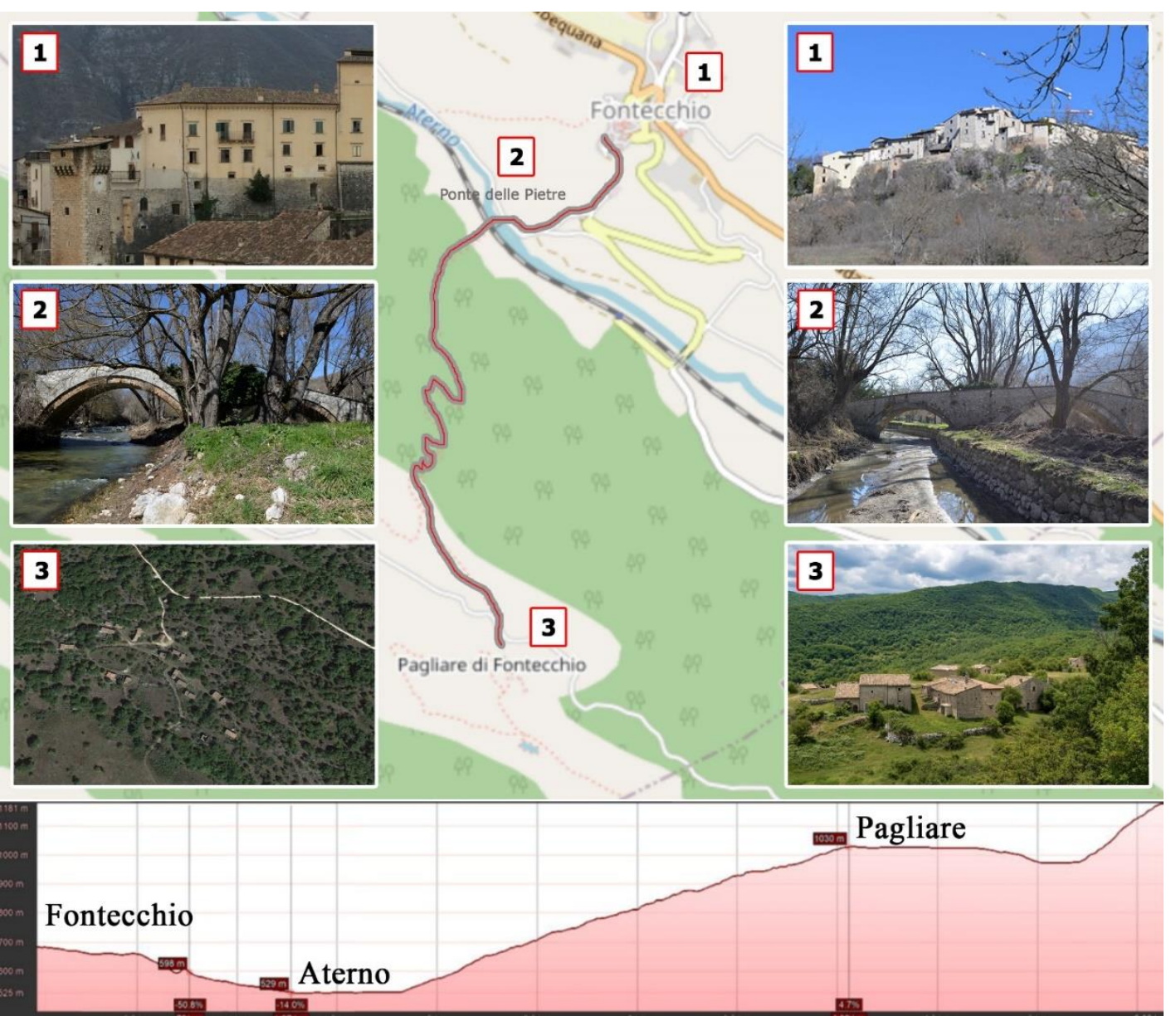

Figure 1. General view of the area analysed with some images of its cultural heritage.

The vaults are built with well-squared limestone blocks, while the masonry walls are made of limestone with different shapes and sizes, arranged on sub-horizontal joints and bedded with copious mortar. As the structure of the bridge is concerned, the digital model is designed to reflect the level and the detail of the available data in time. In this case, the digital model has been implemented according to an extended and comprehensive historical research in the area of the construction materials and technology. This is not a limitation of the approach, since this fits the knowledge path recommended by relevant National and International codes of practice on the management and assessment of existing valuable constructions (ICOMOS, 2003; Directive, 2011) and bridges (Ministerial Decree 578, 2020). Moreover, this way of tackling the survey and modelling of the asset complies with the need of preserving and limiting the impact of diagnostic actions on the asset, so that the safety and the conservation can be combined.

The stratigraphic analysis of the masonry did not highlight masonries units belonging to different phases but pointed out the traces of conservative restoration actions consisting in the massive repair of the joints on the parapet walls and the integration of the North vault with the cement material. This contemporary intervention suggests the partial collapse of the aforementioned arch, already historically documented in an informal inspection performed by Giuseppe Liberatore in 1824 during a study to evaluate the navigability of the Aterno-Pescara river (Liberatore, 1839).

The analysis of the deterioration of the surfaces has pointed out the widespread presence of a patina on the masonry surface due to the natural action that has caused, in some points, the chromatic alteration of the material. Moreover, infesting vegetation is widespread and significantly affected the masonry, biological patina can be observed favouring mould, fungi and bacteria and causing in some areas stains, as well as the efflorescence are widespread on the vaults and walls due to humidity and meteoric phenomena. In some parts of the northern vault, in particular in the modern reconstruction, the analysis points out lacks and detachment, with exfoliation of the cement coating surface layer. In the complex, the artefact has a good state of conservation, probably due to the constant maintenance carried out by the people of Fontecchio that used the crossing structure for access to the "Pagliare", used according to oral sources until the first half of the last century and today part of a "slow" tourism network.

\section{FROM THE SURVEY TO THE HBIM MODEL OF THE BRIDGE}

An operational workflow was defined to develop innovative digital tools that support e-conservation and e-government (Figure 2). This workflow facilitates the combination and integration within digital applications and models of the heterogeneous data resulting from the multidisciplinary analysis. Therefore, the procedure was implemented from the census and analysis of different historical infrastructures located along the Aterno river, extending the knowledge and documentation phases to the Ponte delle Pietre. In such a way, the bridge Virtual Tour and parametric model were developed and was defined an efficient approach for creating a digital support system for the management and conservation of historical infrastructures.

After the first knowledge analysis carried out on the bridge, the 
geometric-formal data were acquired and processed to develop the digital model of the structure and have a complete and integrated view of the examined asset.

The stereometric survey of the bridge was performed by combining the laser scanning (TLS) and terrestrial photogrammetry procedures to obtain a reliable survey from the metric point of view and high-quality photo plans for thematic mapping, taking particular attention to material degradation analysis.

The laser scanning acquisition was carried out in a single survey campaign with a FARO Focus S70 scanner, equipped with an integrated camera with HDR functionality. The scanning parameters, definition, quality, and HDR, were set according to the size and complexity of the surveyed spaces. The postprocessing of the data proceeded with SCENE 2018 software carrying out the automatic registration of the scans, aided by spherical targets, and processing the point cloud of about 52 million points (Figure 3).

During point cloud acquisition, performed through 13 stations, a rectangular image was acquired for each station point and resized for developing a Virtual Tour (Fabbrocino et al., in review). The spherical panoramas were edited with the results of the multidisciplinary analyses and included in a virtual setting that facilitates data management through links to digital tools and online repositories (Figure 4).

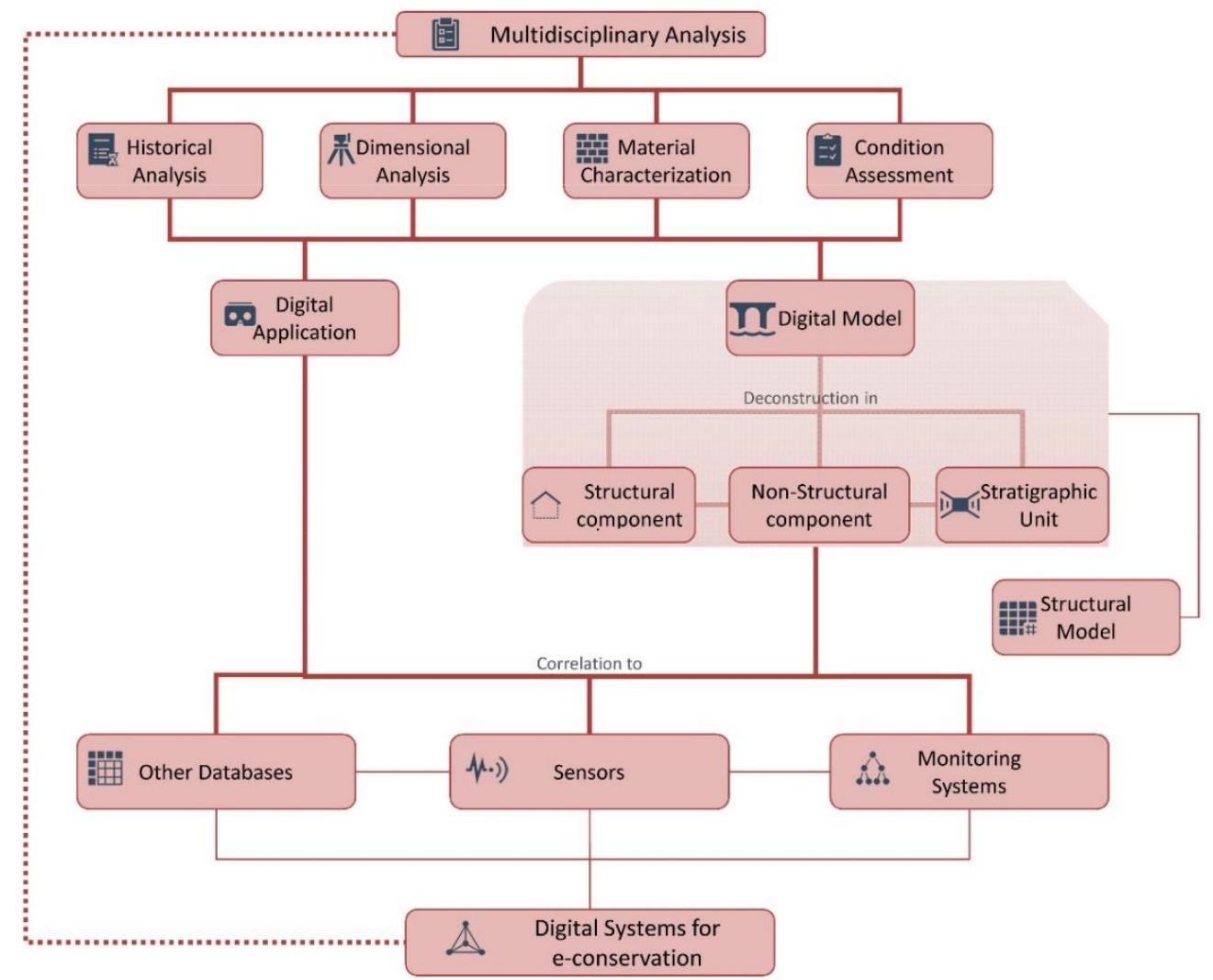

Figure 2. Workflow to develop digital systems for e-conservation.
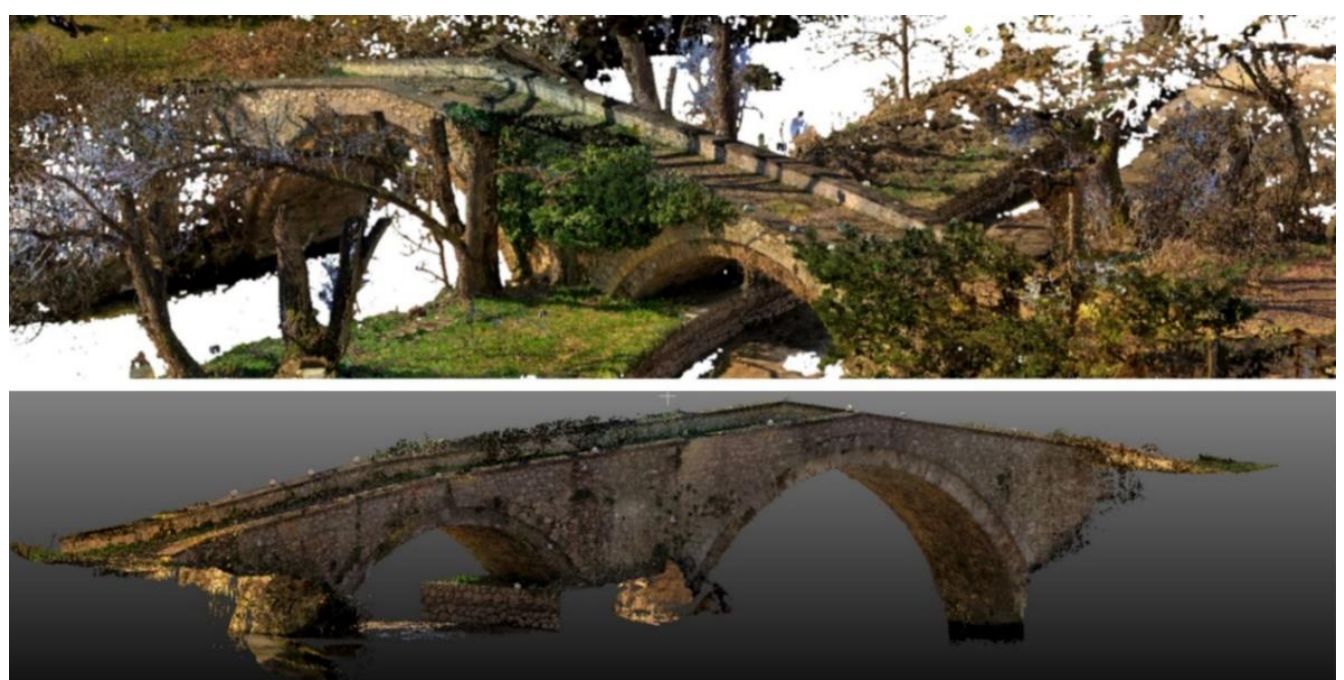

Figure 3. TLS point cloud. 


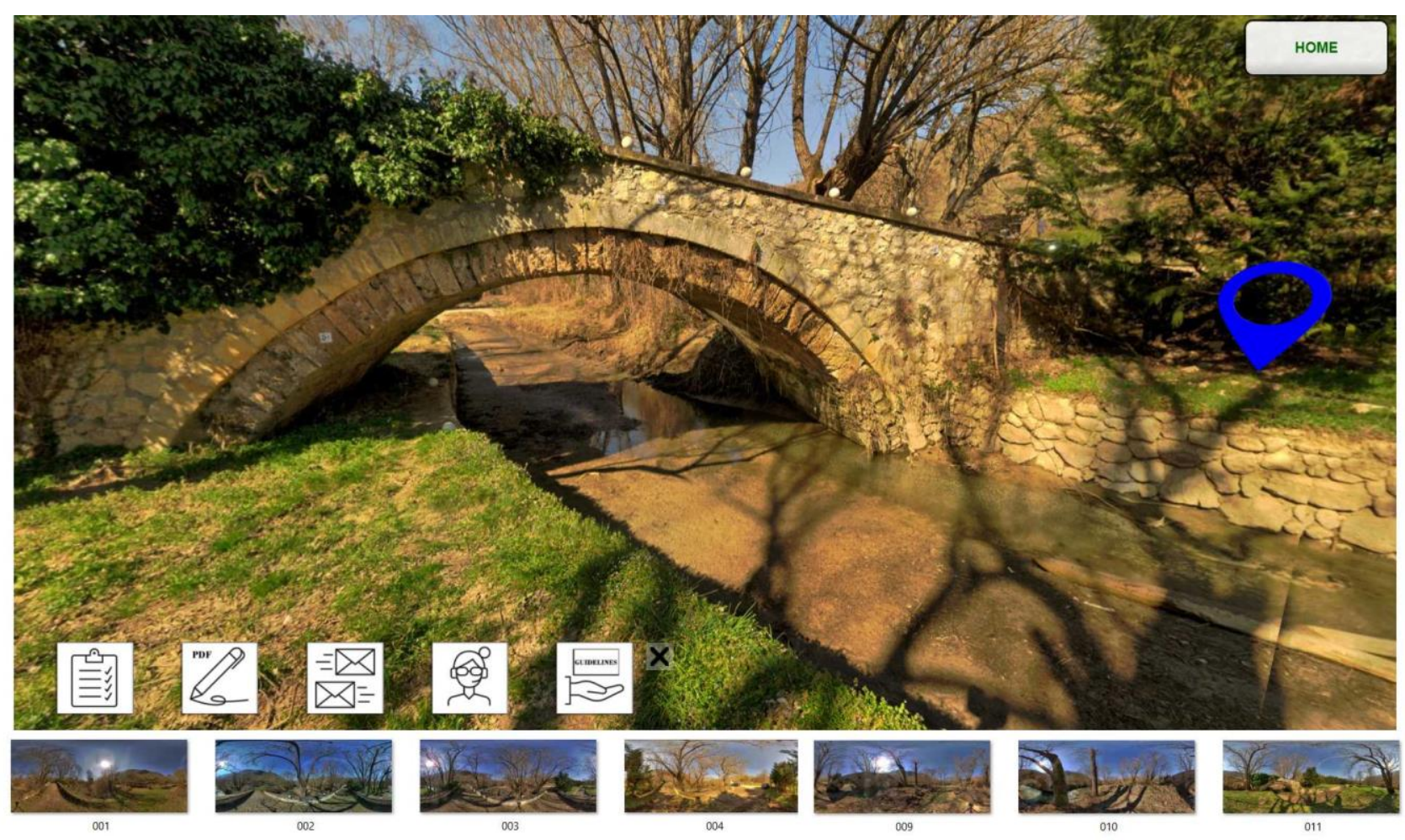

Figure 4. Informative Virtual Tour of the bridge.

On the other hand, the photogrammetric survey was performed starting from 396 digital images set acquired in a single photographic campaign with a Nikon D610. The images were processed with the software Agisoft Metashape Professional 1.5.1 creating two distinct chunks, which were then joined together to obtain, from a cloud of about 108 million points, a total mesh model of more than 5 million faces. The mesh model enables the creation of high-resolution photo plans used to assess, through the analysis of degradation, the state of conservation of the work (Figure 5).

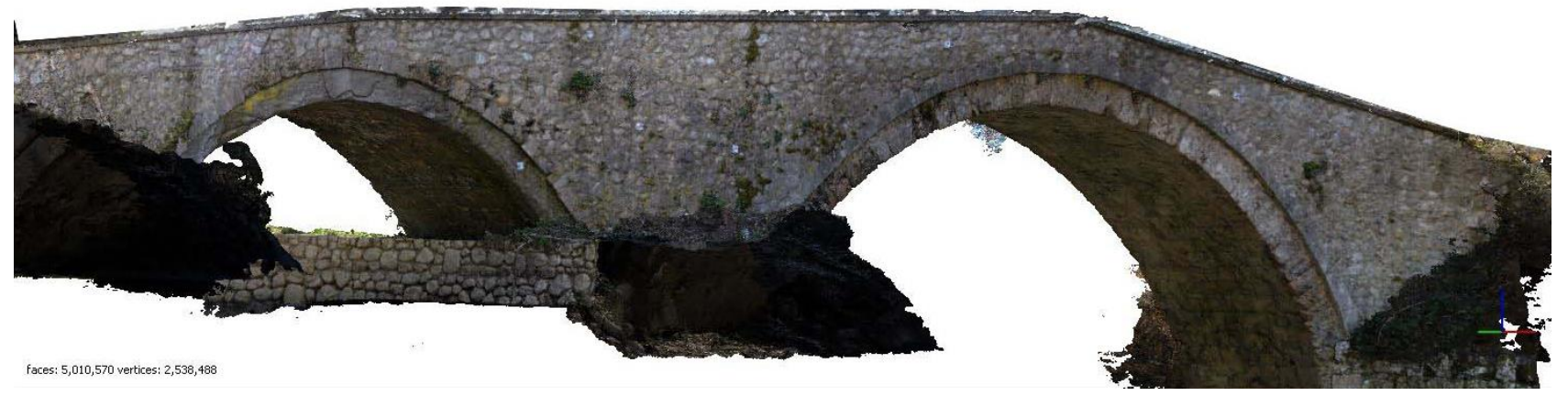

Figure 5. Photogrammetric model of the bridge.

Moreover, the point cloud obtained from the laser scanner survey, the photogrammetric model and the Virtual Tour Information were used as support to create the parametric model of the bridge (Figure 6). The parametric modelling was carried out after critical analysis and segmentation of the elements characterizing the point cloud. The parametric model of the bridge (Figure 7) was performed with the Autodesk Revit software, deconstructing the case study according to the constructive, structural, geometric, and typological features, and recurring to specific families and local models for the vaults and fill modelling. The modelling of structure based on metric data, derived from the integrated survey, and information concerning material and construction techniques, acquired through the multidisciplinary analysis, allowed the development of a parametric model with a high level of geometric detail (LoG), in agreement with those defined at a regulatory level within Building Information Modelling for the new building (UNI 11337, 2018). Indeed, each modelled element was enriched by geometric characteristics, structural materials and stratigraphies, as well as the thicknesses and finishes of all the component elements.

New parameters were associated with each element modelled for enriching the information already collected in the model with those derived from the multidisciplinary research (Guzzetti et al., 2021), achieving a broad level of information (LoI). 


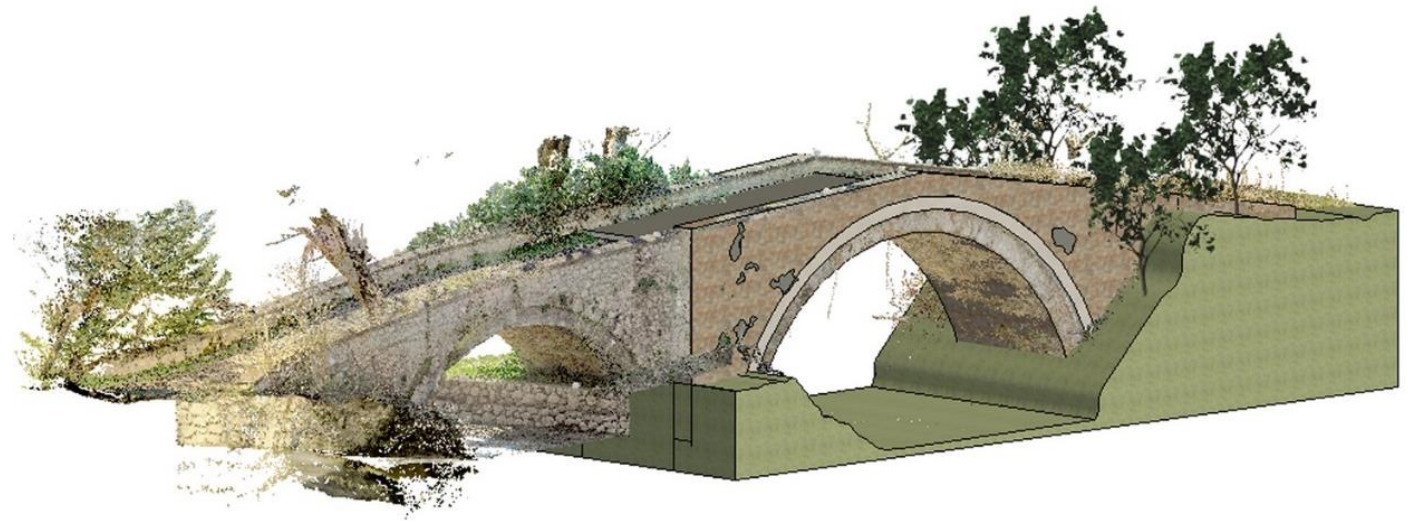

Figure 6. TLS point cloud in BIM environment as reference for developing HBIM model of the bridge.

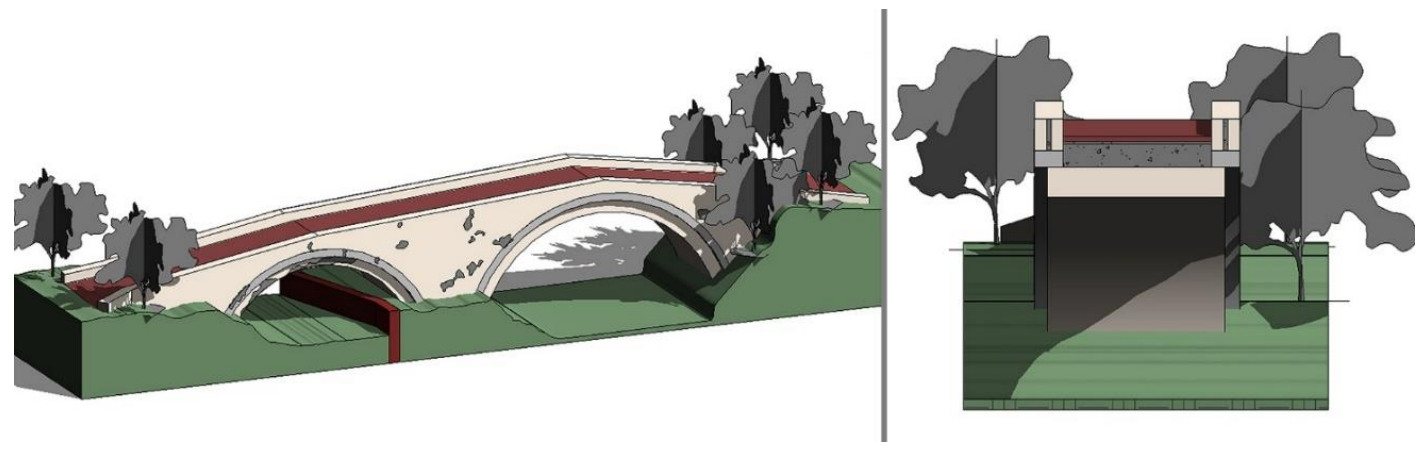

Figure 7. HBIM model: on the left, 3D view; on the right, section view.

At the same time, surfaces of the defects detected in the analysis of the conservation state of the work were modelled using the photo-planes previously made, as experimented for the archaeological analysis of masonry and material degradation (Continenza et al., 2018). In this phase, defect parameters were defined as required by the Guidelines for Risk Classification and Management, Safety Assessment and Monitoring of Existing Bridges (Ministerial Decree 578, 2020). In particular, the parameters describing the type of degradation detected (Defect) and the coefficients of extension (K1-Extent), intensity (K2-Intensity) and the weight attributed to the single defect ( $G$ Defect weight) were specified (Figure 8). The integration of these data within the model, in line with the recommendations of the Guidelines (Ministerial Decree 578, 2020), provides for the evaluation of the relative defect index (DR-Relative Defect Index parameter), transforming the parametric model into a useful tool for the assessment of the conservation state of the artefact based on the information resulting from visual inspections.

Finally, to manage in a coherent and single way all the information concerning the inspections, two different parameters have been defined to correlate the model to the census and inspection forms of the bridges stored in a cloud (Figure 9), to make them accessible to all professionals involved in the process of analysis and evaluation for the conservation of the artefact.

The accuracy achieved in the modelling and digitisation of geometric and non-geometric attributes, including information concerning the transformative history and the state of conservation and damage, has enabled the development of a parametric model representative of the historical artefact. This model can be also used in numerical modelling software for assessing, in a quantitative manner, the behaviour and structural performance of the asset. Finally, the availability of qualitative, metric and structural information within a single model facilitates the drafting of diagnostic investigation plans and becomes functional for the design of ordinary and extraordinary maintenance interventions ensuring the preservation of technical documentation. Therefore, the parametric model is a hub capable of managing and disseminating information between decision and project managers; its integration within complex information systems supports visual inspection operations and the identification of actions to be performed. Indeed, the data collected within the model can be updated over time and effectively organised according to the issues of interest; therefore, the model will always be representative of the real conditions of the artefact of interest.

\section{CONCLUSIONS}

The inner areas of the Abruzzo Apennines are characterized by the widespread presence of small historical centres that in the past decade have been severely affected by seismic events and are currently involved in the process of reconstruction of the architectural heritage. These villages, affected by a previous state of abandonment and characterized by a socioeconomic and cultural context that often has some critical issues, have undergone growth in the summer season of 2020 , following the different tourist preferences due to the SARSCoV-2 pandemic. This has confirmed the value of the inner areas but, at the same time, has pointed out the difficulties related to the tourist accommodation and the lack of cultural services. The discussion developed here, in the perspective of e-government, aims to provide useful tools not only for the preservation of heritage but also for tourist fruition of the territory characterized by the presence of rich cultural heritage, tangible and intangible, weakly valued due to limited social, cultural and economic resources. 


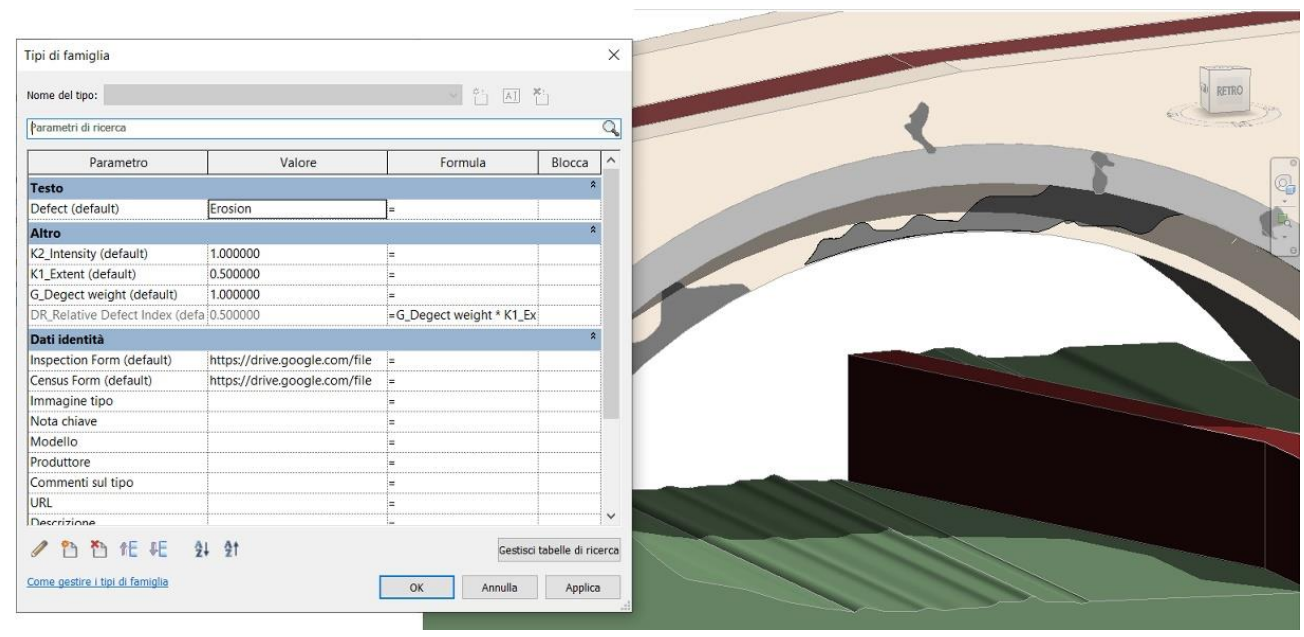

Figure 8. Creation of new parameters according to visual inspection guideline.

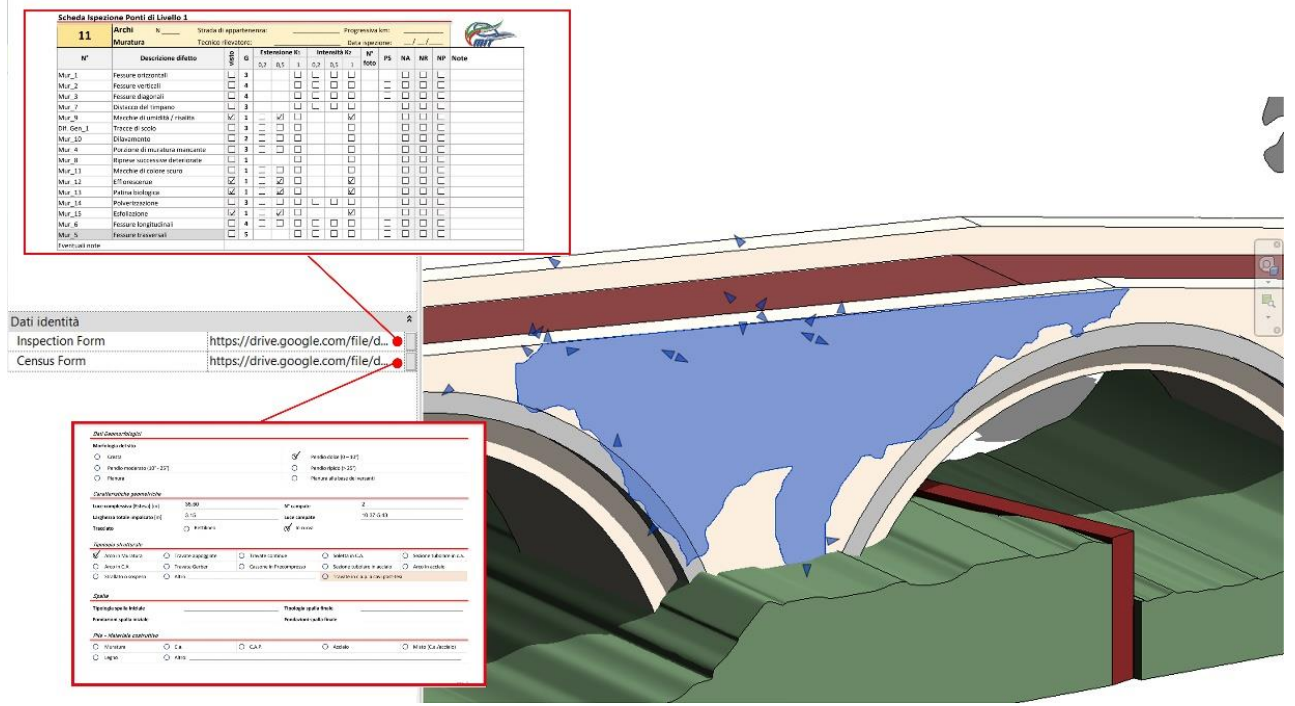

Figure 9. Model correlation to forms shared in a storage cloud.

\section{ACKNOWLEDGMENTS}

This study has been carried out under the PON RICERCA E INNOVAZIONE 2020 E FSC "INSIST" code ARS01_00913, whose financial support is acknowledged. The authors are also grateful to the municipal administration of Fontecchio (AQ), in particular the mayor Dr Sabrina Ciancone, and the Superintendence of Archaeology, Fine Arts and Landscape for the city of L'Aquila and Crater, especially to the Area Officer Arch. Antonio Di Stefano, for granting permission to study the bridge.

\section{CREDITS}

The research presented is the result of authors' collective work, of continuous comparison and of a common discussion. Ilaria Trizio wrote section 1 and supervised the paper. Francesca Savini wrote section 3 and implemented the photogrammetric model. Adriana Marra wrote sections 4 and implemented the parametric model. Giovanni Fabbrocino supervised the research and reviewed the work. All the authors wrote sections 2 and 5.

\section{REFERENCES}

Banfi, F., Barazzetti, L., Previtali, M., Roncoroni, F., 2017. Historic BIM: A New Repository for Structural Health
Monitoring. Int. Arch. Photogramm. Remote Sens. Spat. Inf. Sci. I 42, 269-274.

Conti, A., Fiorini, L., Massaro, R., Santoni, C., Tucci, G., 2020. HBIM for the preservation of a historic infrastructure: the Carlo III bridge of the Carolino Aqueduct. Appl Geomat.

Continenza, R., Redi, F., Savini, F., Tata, A., Trizio, I., 2018. HBIM for the Archaeology of Standing Buildings: Case Study of the Church of San Cipriano in Castelvecchio Calvisio (L'Aquila, Italy). In Fogliaroni P., Ballatore A., Clementini E. (Eds), Proceedings of Workshops and Posters at the 13th International Conference on Spatial Information Theory (COSIT 2017), pp. 315-323, Springer, Cham.

Dall'O' G., Zichi A., Torri M., 2020. Green BIM and CIM: Sustainable Planning Using Building Information Modelling. In Dall'O' G. (Eds.), Green Planning for Cities and Communities. Research for Development, Springer, Cham.

De Luca, L., 2011. Verso la caratterizzazione semantica di rappresentazioni digitali di artefatti architettonici: linee programmatiche di ricerca. Disegnarecon, 99-106. 
Directive, 2011. Directive of the Prime Minister February 09, 2011. Guidelines for the assessment and the mitigation of seismic risk of cultural heritage with reference to Italian NTC2008, G.U. n. 24, January 29, 2011, Rome (in Italian).

Fabbrocino, G., Savini, F., Marra, A., Trizio, I., in review. Virtual investigation of masonry arch bridges: digital procedures for inspection, diagnostics, and data management. In Proceedings of EuroStruct - European association on quality control of bridges and Structures.

Guzzetti, F., Anyabolu, K.L.N., Biolo, F., D'Ambrosio, L., 2021. BIM for Existing Construction: A Different Logic Scheme and an Alternative Semantic to Enhance the Interoperabilty. Appl. Sci., 11, 1855.

ICOMOS, 2003. Principles for the Analysis, Conservation and Structural Restoration of Architectural Heritage, <https://www.icomos.org/en/resources/charters-and-texts>, (17 February 2021).

Inglese, C., Paris, L. (Eds.), 2020. Arte e Tecnica dei Ponti Romani in Pietra. Sapienza Università Editrice, Roma.

Liberatore, G., 1839. Navigazione della Pescara. Problema. Opuscoli vari, vol. 2, Tip. Rietelliana, Aquila.

Lubowiecka, I., Arias, P., Riveiro, B., Solla, M., 2011. Multidisciplinary Approach to the Assessment of Historic Structures Based on the Case of a Masonry Bridge in Galicia (Spain). Computers \& Structures 89, 1615-1627.

Maietti, F., Di Giulio, R., Medici, M., Ferrari, F., Ziri, A. E., Turillazzi, B., Bonsma, P., 2020. Documentation, Processing, and Representation of Architectural Heritage Through 3D Semantic Modelling: The INCEPTION Project. In Bolognesi, C. M., Santagati, C. (Eds.), Impact of Industry 4.0 on Architecture and Cultural Heritage, pp. 202-238, IGI Global, Hershey.

Marchetti, A., Redi, F., Savini, F., Trizio, I., Giannangeli, A., 2017. La chiesa di San Cipriano a Castelvecchio Calvisio (AQ) nella Baronia di Carapelle: documentazione speditiva e analisi stratigrafica 3D del manufatto. Archeologia dell'Architettura, XXII, 239-253.

Marra, A., Trizio, I., Fabbrocino, G., in press. Digital Tools for the knowledge and safeguard of historical heritage. In Proceedings of 8th Civil Structural Health Monitoring Workshop (CSHM-8).

Marra, A., Trizio, I., Savini, F., Ruggieri, A., Fabbrocino, G., in press. Una procedura per L'Historic Digital Twin (HDT) dei ponti ad arco in muratura. In Empler T. (Ed.), 3D Modelling \& BIM. Digital Twin.

Messaoudi T., Véron, P., Halin, G., De Luca, L., 2018. An ontological model for the reality-based $3 \mathrm{D}$ annotation of heritage building conservation state. Journal of Cultural Heritage, 29, 100-112.

Migliario, E., 1995. Uomini, terre e strade. Aspetti dell'Italia centro appenninica fra antichità e alto medioevo. Edipuglia, Bari.

Ministerial Decree 578, 2020. Linee Guida per la Classificazione e Gestione del Rischio, la Valutazione della Sicurezza ed il Monitoraggio dei Ponti Esistenti,
$<$ https://www.mit.gov.it/normativa/decreto-ministeriale-numero578-del-17122020> (17 February 2021).

OECD, 2020. Digital Government Index: 2019 results, OECD Public Governance Policy Papers, No. 03, OECD Publishing, Paris.

Omer, M., Margetts, L., Mosleh, M.H., Hewitt, S., Parwaiz, M., 2019. Use of gaming technology to bring bridge inspection to the office. Structure and Infrastructure Engineering 15(10), 1292-1307.

Pepe, M., Costantino, D., Restuccia Garofalo, A., 2020. An Efficient Pipeline to Obtain 3D Model for HBIM and Structural Analysis Purposes from 3D Point Clouds. Appl. Sci. 10 (4), 1235 .

Previtali, M., Barazzetti, L., Banfi, F., Roncoroni, F., 2019. Informative content models for infrastructure load testing management: the Azzone Visconti bridge in Lecco. Int. Arch. Photogramm. Remote Sens. Spatial Inf. Sci. XLII-2/W11, 995-1001.

Rainieri, C., Gargaro, D., Fabbrocino, G., Maddaloni, G., Di Sarno, L., Prota, A., Manfredi, G., 2018. Shaking table tests for the experimental verification of the effectiveness of an automated modal parameter monitoring system for existing bridges in seismic areas. Structural Control and Health Monitoring 25(7), e2165.

Savini, F., Rainieri, C., Fabbrocino, G., Trizio, I., 2021. Applications of Stratigraphic Analysis to Enhance the Inspection and Structural Characterization of Historic Bridges. Infrastructures 6(7).

Solla, M., Caamaño, C., Riveiro, B., Lorenzo, H., 2011. GPR analysis of a masonry arch for structural assessment. In 2011 6th International Workshop on Advanced Ground Penetrating Radar (IWAGPR), Aachen, pp. 1-6.

Trizio, I., Savini, F., Giannangeli, A., Fiore, S., Marra, A., Fabbrocino, G., Ruggieri, A., 2019a. Versatile tools: digital survey and virtual reality for documentation, analysis and fruition of cultural heritage in seismic areas. Int. Arch. Photogramm. Remote Sens. Spatial Inf. Sci. XLII-2/W17, 377384

Trizio, I., Savini, F., Giannangeli, A., Boccabella, R., Petrucci, G., 2019b. The archaeological analysis of masonry for the restoration project in HBIM. Int. Arch. Photogramm. Remote Sens. Spatial Inf. Sci. XLII-2/W9, 715-722.

Trizio, I., Brusaporci, S., Savini, F., Maiezza, P., Tata, A., Giannangeli, A., 2020. Advanced Digital Processes for the Survey: Analysis and Conservation of Built Heritage. In C.M. Bolognesi, C. Santagati (Eds.), Impact of Industry 4.0 on Architecture and Cultural Heritage, pp. 76-110, IGI Global, Hershey.

UNI 11337, 2018. Building and civil engineering works - Digital management of the informative, UNI, Ente Nazionale di Normazione.

Zenodocchio, S., 2008. Antica viabilità in Abruzzo. Rea edizioni, L'Aquila. 